\title{
Anticorrosion Properties of Waterborne Polyurethane Coating Containing Caffeate Anions Intercalated LDH
}

\author{
Haichao Zhao ${ }^{1}$ Wenru Zheng ${ }^{1}$, Wenjing Liu ${ }^{1}$, Xin Zhang ${ }^{1}$, Yue Su ${ }^{1,2, *}$ \\ ${ }^{1}$ Key Laboratory of Marine Materials and Related Technologies, Zhejiang Key Laboratory of Marine \\ Materials and Protective Technologies, Ning--bo Institute of Materials Technology and Engineering, \\ Chinese Academy of Sciences, Ningbo 315201, China \\ ${ }^{2}$ University of Chinese Academy of Sciences, Beijing 100049, China \\ *E-mail: suyue@nimte.ac.cn
}

Received: 7 July 2021 / Accepted: 17 August 2021 / Published: 10 September 2021

\begin{abstract}
LDH with caffeate anions intercalation was successfully prepared by acidification of LDH and followed ionic exchange process. Waterborne polyurethane based coatings withouth and with $0.5 \mathrm{wt} \% \mathrm{LDH}$ and $0.5 \mathrm{wt} \%$ caffeate anions intercalated LDH (LCA) were fabricated with the thickness of $70 \pm 4 \mu \mathrm{m}$. EIS and LEIS were used to characterize the electrochemical and micro-area corrosive behavior of LDHdoped coatings. It displayed that the addition of LDH loaded with caffeate anions improved the impedance of PU from $1.47 \times 10^{7}$ to $3.93 \times 10^{7} \Omega \mathrm{cm}^{2}$ after 30 days immerion in $3.5 \% \mathrm{NaCl}$ solution. In addition, the micro-area corrosive condition of LCA containing PU is better than that in pure PU and LDH containing PU coating, which could ascribe to the emancipation of intercalated caffeate ions in LDH. The addition of LCA nanohybrids into PU could enhance the barrier performances of PU. Moreover, the excellent ions exchanges ability of LDH could be used to adsorb chloride ions, and the release of caffeate anions could delay the process of corrosion reactions. The synergistic effect of caffeate anions and LDH improves the anti-corrosion performance of waterborne PU.
\end{abstract}

Keywords: barrier effect, ionic exchange, waterborne polyurethane coating

\section{$\underline{\text { FULL TEXT }}$}

(C) 2021 The Authors. Published by ESG (www.electrochemsci.org). This article is an open access article distributed under the terms and conditions of the Creative Commons Attribution license (http://creativecommons.org/licenses/by/4.0/). 